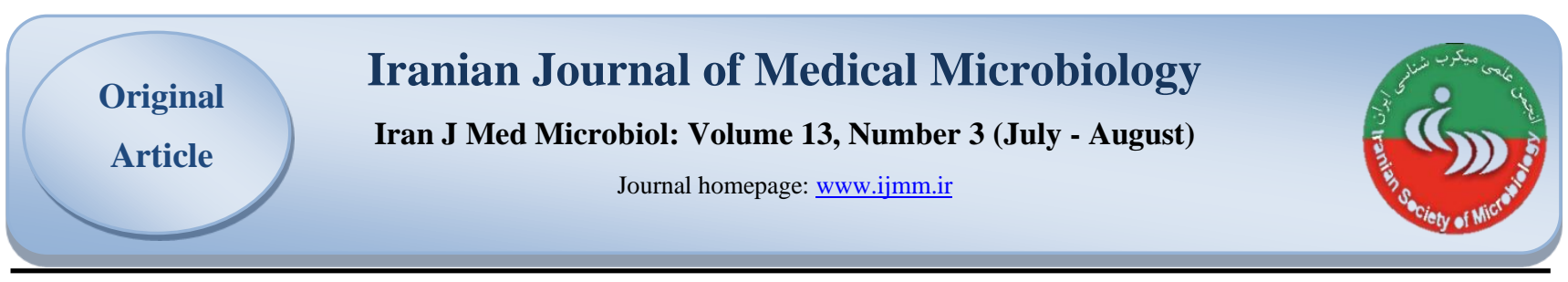

\title{
Investigating the Presence of Type IV Pilin Subgenus in Pseudomonas aeruginosa Isolated from Cystic Fibrosis, Burns and Environmental Samples
}

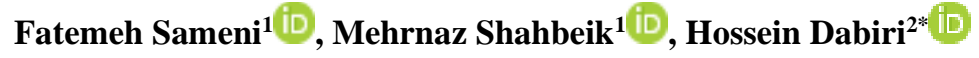 \\ 1.Department of Microbiology, Faculty of Advanced Sciences \& Technology, Pharmaceutical \\ Sciences Branch, Islamic Azad University, Tehran, Iran \\ 2.Department of Clinical Microbiology, School of Medicine, Shahid Beheshti University of Medical Sciences, Tehran, Iran
}

Article Information

\section{Article Subject:}

Medical Bacteriology

dei $10.30699 / \mathrm{ijmm} .13 .3 .164$

Corresponding author:

\section{Hossein Dabiri,}

Department of Clinical

Microbiology, School of

Medicine, Shahid Beheshti

University of Medical Sciences,

Tehran, Iran

Email:

$\underline{\text { hodabiri@gmail.com }}$

Use your device to scan and read the article online

\section{Abstract}

Background and Aims: The type IV Pilin is an important colonization factor for opportunistic pathogens of Pseudomonas aeruginosa, which plays a role in the formation of biofilms and binding to the host cells. Each type of Pilin is coded with a particular auxiliary gene. This specific relationship can be used as a therapeutic target for detecting $P$. aeruginosa strains as well as its molecular classification. The purpose of this study was to evaluate the frequency of different types of auxiliary genes in cystic fibrosis, burns, and environmental samples.

Materials and Methods: Pseudomonas aeruginosa samples were collected from patients with cystic fibrosis, burns as well as environmental wastewaters during 2016-2017. Samples were cultured and identified using standard microbial and biochemical methods. DNA extraction was performed by boiling and PCR was performed through specific primers.

Results: Totally, 90 isolates of $P$. aeruginosa samples (35 environmental, 30 burns, and 25 cystic fibrosis) were examined. $t f p O$ and $t f p Z$ were positive in 71 and 2 isolates, respectively.

Conclusion: The results indicated that Pseudomonas aeruginosa Pilin types are very diverse. Regardless of the source of the samples, the most common tfp was tfpO. Taking into account the fact that $t f p Z$ was found only in burns, it can be assumed that this particular type may appear in severe clinical conditions. Ultimately, larger statistical population and use of more comprehensive typing methods is suggested for better results.

Keywords: Pseudomonas aeruginosa; Type IV Pilin, Cystic fibrosis

Received: $2019 / 05 / 14$

Accepted: 2019/08/24

Available online: 2019/08/24

Copyright $\odot$ 2019. This is an open-access article distributed under the terms of the Creative Commons Attribution- 4.0 International License which permits Share, copy and redistribution of the material in any medium or format or adapt, remix, transform, and build upon the material for any purpose, even commercially.

How to cite this article:

Sameni N, Shahbeik M, Dabiri H. Investigating the Presence of Type IV Pilin Subgenus in Pseudomonas Aeruginosa Isolated from Clinical and Non-Clinical Samples. Iran J Med Microbiol. 2019; 13 (3) :164-174

Download citation:

$\underline{B i b T e X}|\underline{R I S}| \underline{E n d N o t e}|\underline{\text { Medlars }}| \underline{\text { ProCite } \mid}$ Reference Manager $\mid \underline{\text { RefWorks }}$

Send citation to:

Mendeley 2 Zotero $(1)$ RefWorks 


\section{Introduction}

Pseudomonas is a Gram-negative, aerobic, non-spore forming, oxidase positive, catalase positive bacteria belonging to the family Pseudomonadaceae (1). Pseudomonas aeruginosa is an important opportunistic pathogen among cystic fibrosis and burnt patients and can be colonized in hospital sewage systems and enter the environment (2). The pathogenesis of P. aeruginosa is due to the production of several cellular and extracellular virulence factors. The cellular factors include flagellum, pyocyanin, fimbria and lipopolysaccharide, and pili, among which bacterial type IV pilus (Tfp) is one of the most important and necessary factors for multiple cellular functions, including biofilm formation, surface motility, hostcell binding, adhesion, cell signaling, DNA uptake by natural transformation (3). Two models of Oglycosylation systems have been found in $P$. aeruginosa. In the first model, glycosylation happens through TfpO (Pil O). The Pil $\mathrm{O}$ is an Oligo-saccharyl-transferase that transfers an antigen-O unit to the serine amino acid placed at the C-terminal of the group I pilins. The second pilin glycosylation system in $P$. aeruginosa was found in strains IV, Pa5196 and Pa7, which lacked TfpO (6). $P$. aeruginosa has been separated into five groups according to the presence or absence of varying downstream accessory genes adjacent the pilin gene, pilA .The PilA pilins have different lengths, amino acid sequences and posttranslational modifications.

The first recognized groups are groups I and II. Strains PA01, PAK, and PA103 express group II pilins. Spangenberg and colleagues showed that Type III polymorphism has 173 amino acids, which is taller than the prior pilins, and an open-ended read-only template with undefined function, now called TfpY, which lies under the PilA gene. More isolates with group III alleles, as well as isolates with 2 new pilin alleles (groups III and IV), were found in more than 300 strains of $P$. aeruginosa. The strains of the group $\mathrm{V}$ pilin express the auxiliary pilin and protein (Tfp Z) as group III. The group IV pilin consists of two isolates (Pa97, Pa5196) that code the TfpW and TfpX auxiliary proteins at the downstream of the PilA4 (9).

Considering that type IV pilin is one of the most important structures of $P$. aeruginosa, its presence and variation may contribute to the pathogenesis of the isolates possessing it. This pilin may also act as a new target for antibiotic therapy which has been recently very challenging worldwide (10-12). Hence we aimed to study the presence of type IV pilin subtypes among $P$. aeruginosa isolates from three different sources; hospital waste water, burnt and cystic fibrosis patients.

\section{Material and Methods}

Totally, 90 isolates of $P$. aeruginosa strains; 35 from environmental samples, 30 from burnt patients and 25 from cystic fibrosis children referred to Mofid Hospital of Tehran, Iran, were isolated from November 2015 to December 2016. Sampling was done under sterile conditions and the samples were immediately transferred to the laboratory of Shahid Beheshti University of Medical Sciences at the Faculty of Medicine. Sputum specimens of patients with cystic fibrosis were inoculated into McCanky agar and blood agar medium and incubated at $37^{\circ} \mathrm{C}$ for 24 hours. Finally, the isolates were identified as $P$. aeruginosa using microbial and biochemical methods such as oxidase and catalase, TSI and OF, and growth at temperatures of 4 and $41^{\circ} \mathrm{C}$, as well as characteristics such a pigment and odor production . The standard strain of $P$. aeruginosa PAO1 was used as control. P. aeruginosa samples isolated from burnt and cystic fibrosis patients and the environment isolates were stored in TSB containing $30 \%$ glycerol at $-70^{\circ} \mathrm{C}$ until further investigation.

\section{DNA extraction and polymerase chain reaction}

For DNA extraction of the isolates, the boiling technique was applied. For this purpose, $200 \mathrm{ml}$ of sterilized water was added into the micro-tube and 3-4 fresh colonies (24 hour growth) were dissolved in water and the suspensions were kept at $100^{\circ} \mathrm{C}$ for 10 minutes, after which centrifugation at 10,000 rpm was done for 5 minutes, and the supernatant containing DNA was transferred to the new microtubule for PCR. In this study, the presence of the genes encoding two subtypes of type IV pilin including $\mathrm{TfpO}$ and $\mathrm{TfpZ}$ genes were investigated by PCR method using specific primers listed in 
Table 1. The PCR reaction was done in a volume of $25 \mu \mathrm{L}$ and performed as (Amplicon, Iran) $12.5 \mu \mathrm{L}$ Master Mix 1x buffer, $0.5 \mu \mathrm{L}$ of each primer with concentration of $10 \mathrm{mM}, 300 \mathrm{ng} / \mathrm{L}$ DNA, and $4 \mu \mathrm{L}$ deionized distilled water. After preparation of PCR reaction reagents, the microtubules were placed in a Thermocycler machine (Bio Intellectica, Canada). The program for each gene amplification is summarized in Table 2.

Table 1. Nucleotide sequence of the primers of TfpO, TfpZ genes of the type IV pilin.

\begin{tabular}{|c|lc|c|}
\hline Primer & \multicolumn{1}{|c}{ Oligonucleotide sequence ('3-'5) } & Product length (bp) & Reference \\
\hline \multirow{2}{*}{$T f p O$} & $\begin{array}{l}\text { Forward 5'- CGTAGGGCTTGCACTGCTAT-3' } \\
\text { Reverse 5'-AAGAACCCTCCCAACACGAC-3' }\end{array}$ & 363 & $\begin{array}{c}\text { in this } \\
\text { Study }\end{array}$ \\
\hline \multirow{2}{*}{$T f p Z$} & $\begin{array}{l}\text { Forward 5'- AGATTAGGGCGTTCGCTGTT-3' } \\
\text { Reverse 5'- CCGCAGGACATCCATTAGCA-3' }\end{array}$ & 464 & in this \\
\hline
\end{tabular}

Table 2. PCR program for, TfpO and TfpZ Gene amplification.

\begin{tabular}{|c|ccccc|}
\hline Gene & \multicolumn{2}{|c}{ TfpO } & & TfpZ \\
\hline Stages & Temperatur & time & Temperature & time \\
\hline Initial denaturation & e & 95 & $15 \mathrm{~m}$ & 95 & $\mathbf{1 5} \mathbf{~ m i n}$ \\
\hline denaturation & 95 & $30 \mathrm{~s}$ & 95 & $\mathbf{3 0} \mathbf{s}$ \\
\hline Connection & 72 & $30 \mathrm{~s}$ & 72 & $\mathbf{1} \mathbf{~ m i n}$ \\
\hline Elongation & 58 & $30 \mathrm{~s}$ & 60 & $\mathbf{4 5} \mathbf{~}$ \\
\hline Final elongation & 72 & $7 \mathrm{~m}$ & 72 & $\mathbf{7 5}$ \\
\hline Cycle & 35 & 35 & 35 & $\mathbf{3 5}$ \\
\hline
\end{tabular}

After the PCR reaction, electrophoresis of the PCR products was performed on a $1.5 \%$ agarose gel containing safe staining dye and recorded by Gel Documentation (Figures 1 and 2). PCR products were sequenced bi-directionally (the Bioneer Co., Korea) and results were analyzed using the NCBI database. Statistical analysis was performed using SPSS 23 (SPSS Inc. Chicago, Illinois, USA).

\section{Results}

Out of the 90 P. aerosinosa isolates, $72(80 \%)$ possessed the TfpO gene. The results of electrophoresis are shown in Figures 1 and 2 . Based on the differentiation of the studied groups, the frequency of the $\mathrm{TfpO}$ gene in each group was as follows;
Among the 35 environmental samples, 31 strains $(88.57 \%)$ had $\mathrm{TfpO}$ gene and 4 samples (11.42\%) were recognized as negative for this gene. Out of the 25 samples from cystic fibrosis, 17 strains $(68 \%)$ had $\mathrm{TfpO}$ gene and 8 samples (32\%) did not possess this gene. Among the 30 isolates from burnt patients, $24(80 \%)$ had TfpO gene, whilst 6 (20\%) isolates did not have this gene (Figure 1).

The TfpZ gene was positive in $2(2.2 \%)$ out of 90 isolates, regardless of the source of isolates and $88(97.8 \%)$ isolates lacked this gene. The TfpZ gene was negative in isolates from environmental samples as well as patients with cystic fibrosis. Two $(6.66 \%)$ positive strain for TfpZ belonged to isolates from burnt patients $(P>0.05)$ (Figure 2). 


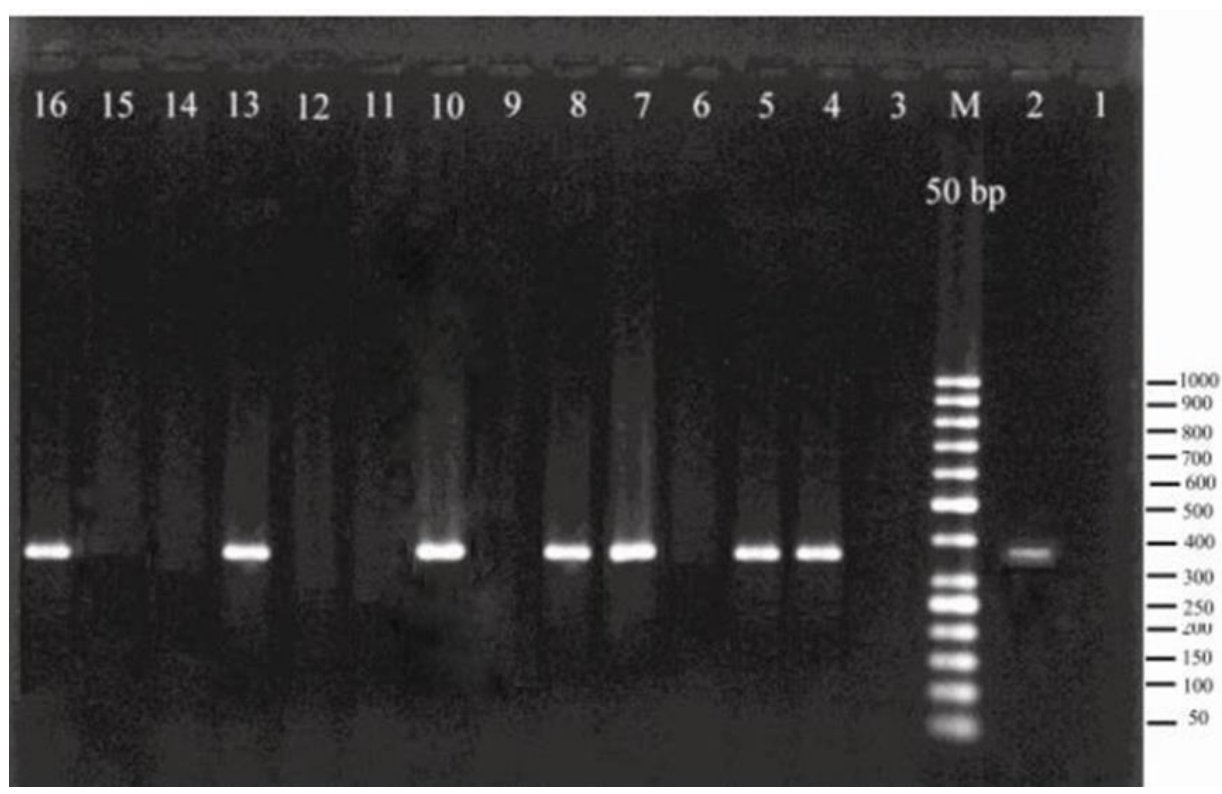

Figure 1. Electrophoresis results of the TfpO gene among $P$. aeruginosa isolates (363bp). Lane 1, negative control; lane 2, positive control; M: size marker of $50 \mathrm{bp}$, lanes 3-16 PCR products of the TfpO.

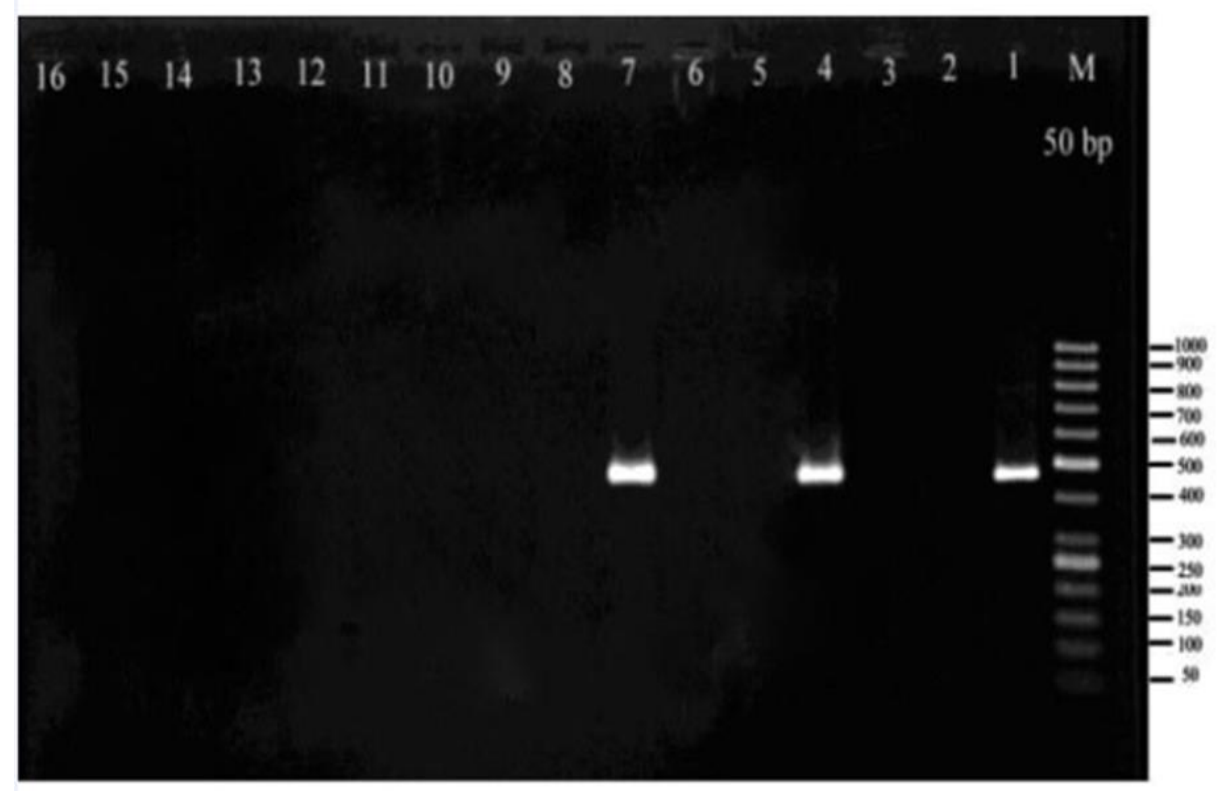

Figure 2. Electrophoresis results of the TfpZ gene of our P. aeruginosa isolates (364bp). Lane 1, positive control; lane 2, negative control; M: size marker of $50 \mathrm{bp}$, lanes 3-16 PCR products of TfpZ gene.

\section{Discussion}

High adaptability, colonization and survival of $P$. aeruginosa is due to its massive sets of chrosomal and non-chromosome DNA fragments and genome-modifying factors such as bacteri- ophages, integrons, transposons, and other elements (13). P. aeruginosa is colonized on different surfaces and the type IV pilin is one of the important factors for colonization. It has now been accepted that $P$. aeruginosa is able to express three distinct 
types of pilin subtypes IVa, IVb and Tad. (14). The IVa type is the most common pilin type in bacteria that grow in laboratories.

To our knowledge, no study has so far been conducted on the comparison of the frequency of type IV pilin in strains and populations of $P$. aeruginosa, and only limited studies have been done on genomic diversity and frequency of IVa pilin subtypes (15-17).

Therefore, the present study was conducted to investigate the presence of IV pilin sub types by PCR among the $P$. aeruginosa community isolated from burnt and cystic fibrosis patients, as well as in the sewage system of the burn centers. According to the results, a high percentage of $P$. aeruginosa strains isolated from different sources in this study were group I of type IV (TfpO). Subsequently, 68\% of the samples isolated from patients with cystic fibrosis had this type of type IV. This finding suggests that strains from environment and burnt patients are more closely related to strains isolated from cystic fibrosis patients. In 2004, Kus et al. found that the prevalence of TfpO in P. aeruginosa strains was more than other groups of type IV pilin (7). According to Kus et al. in 2008, the prevalence of TfpO among cystic fibrosis patients, other clinical samples, and the environmental samples were $69.7 \%, 30.5 \%$, and $58.3 \%$ respectively; which compared to our results, showed a higher prevalence among clinical samples (18). Also Deligiann et al. in 2010 observed that the prevalence of $\mathrm{TfpO}$ in cystic fibrosis isolated $P$. aeroginosa was more than other groups and that it was associated with bacterial colonization (19). Based on the study of Pirnay et al. in 2009, the frequency of $\mathrm{TfpO}$ in cystic fibrosis isolated $P$. aeroginosa was $55.8 \%$, which is somewhat above the average $(48.2 \%)(20)$, but contrary to our study an association between TfpO and cystic fibrosis was not observed. In this study, group V pilin type IV (TfpZ) was only observed in $6.66 \%$ of the samples from burnt patients, and the other isolates did not possess this group of type IV pilin.

\section{Conclusion}

Overall, our study showed that the prevalence of group I type IV pilin (TfpO) was high in the population of Pseudomonas aeruginosa strains isolated from burnt and cystic firbosis patients, as well as environmental samples. Since type IV pilin is involved in a variety of bacterial processes, especially in post-translational modification (pili glycosylation) and biofilm formation, their relatively high prevalence indicates a high level of virulence among the Iranian strains of $P$. aeruginosa studied. Based on the studies and the results obtained, we recommend that further studies with an increased number of samples, a more diverse society, involving more genotypic and phenotypic characteristics of type IV pilin subtypes.

\section{Acknowledgements}

Great thanks to the Department of Microbiology of Shahid Beheshti University of Medical Sciences, for the support and providing the facilities for this work.

\section{Conflict of Interest}

The authors reported no conflict of interest. 


\title{
بررسى حضور زنهاى فرعى بِيلى تيِ جهارم در سويههاى سودوموناس آئروزينوزاى جداشده از نمونهاى بالينى و غيربالينى
}

\author{
فاطمه ثامنى'، مهرناز شاهبيك'، حسين دبيرى זّ"
}

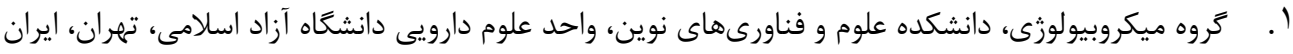

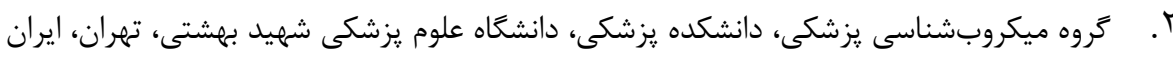

\section{جكيلده}

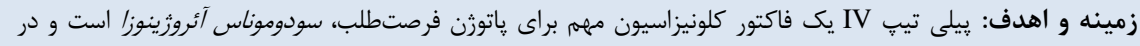

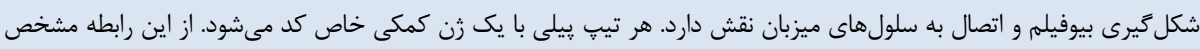

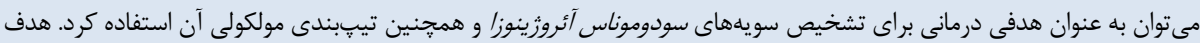

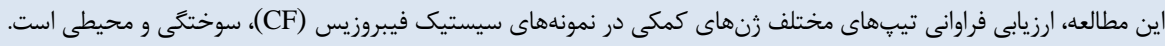

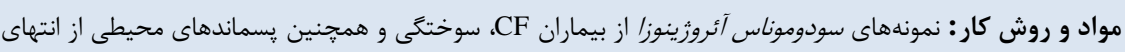

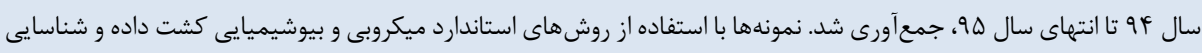

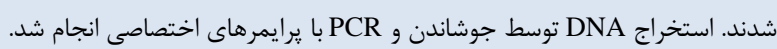

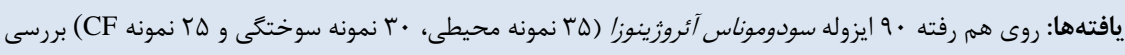

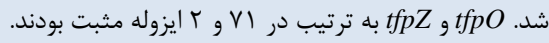

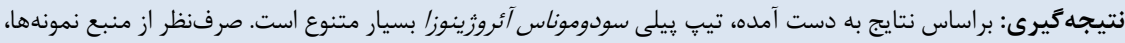

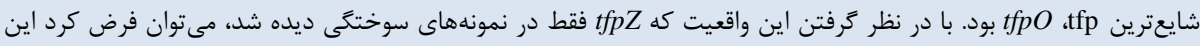

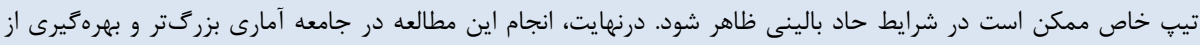

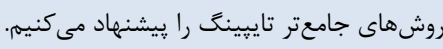
كليد وازهها: سودوموناس آئروزينوزا، يِيلى تيب IV، سيستيك فيبروزيس كجىايت ؟ مجله ميكروبشناسى بزشكى ايران: دسترسى آزاد؛ كيى بردارى، توزيع و نشر براى استفاده غيرتجارى با ذكر منبع آزاد است.

اطلاعات مقاله

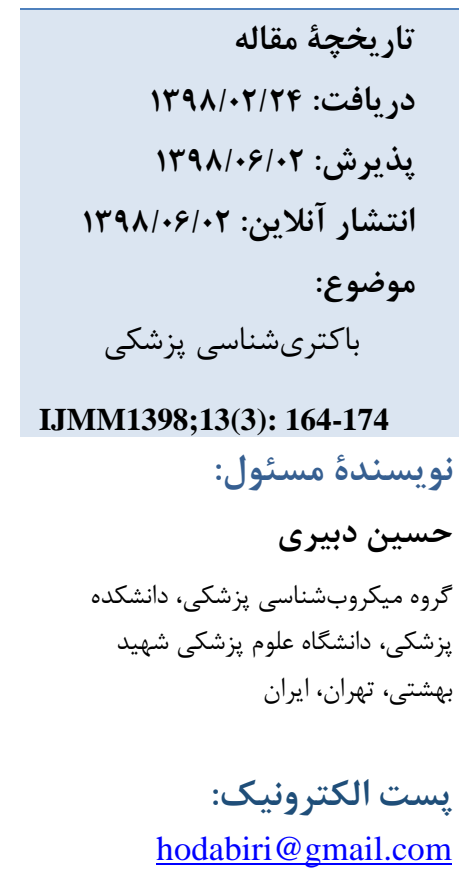

مقدمه

نقش دارند. پِيلى تيٍ جهار سودوموناس آئروزينوزا به عنوان يك عامل اتصالى قدرتمند در انواع محيطها در فرايند اتصال باكترى شركت

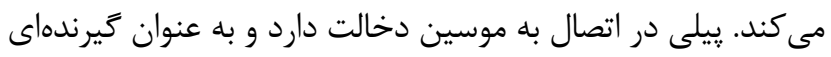
قوى براى ليعاندهاى GM1 و GM2 انسانى در سطح سلولهاى ابيىتليالى محسوب مىشود (ب). به طور كلى، ييلى نوع جهارم به سه

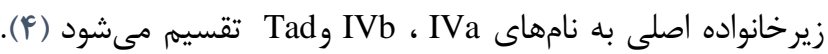

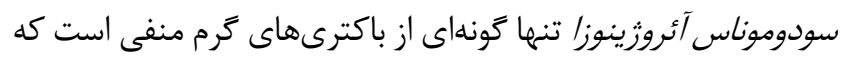
هر سه زيرخانواده از ييلى نوع جهمارم در آن مشاهده شده است (ه). در حالت كلى ييلى نوع جهارم به سه زير خانواده اصلى به نامهاى

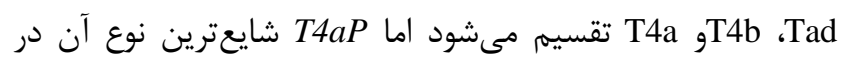

جنس سودوموناس در خانواده سودوموناداسه، شامل باسيلهاى كرم منفى، متحرك، غير اسيد فاست، بدون اسيور، هوازى مطلق،

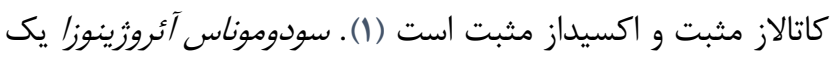

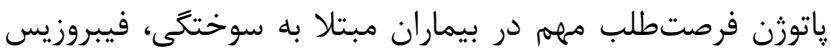
سيستيك تنفسى است و در سيستمههاى فاضلاب بيمارستانى قادر به

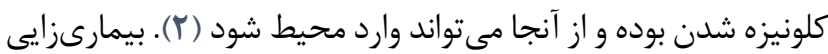
سودوموناس آئروزينوزا به علت توليد جندين فاكتور ويرولانس همراه سلول و فاكتورهاى خارج سلولى است. فاكتور ويرولانس همراه سلول شامل پيلى، فلازل، ييوسيانين، فيمبريه و لييويلى

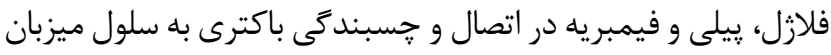




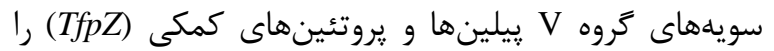

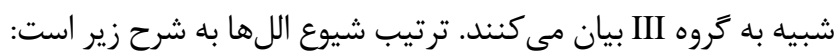

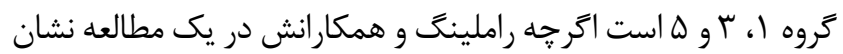

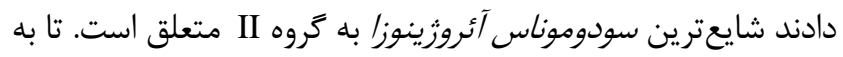

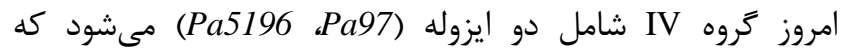
يروتئينهاى كمكى TfpW و TfpX را در קايين دست PilA4 كد

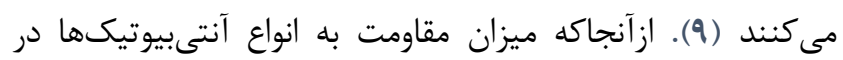

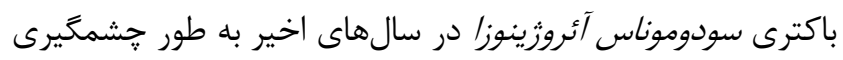
افزايش يافته (r|-•ا() و بر اساس توصيفات فوق و تحقيقات انجام

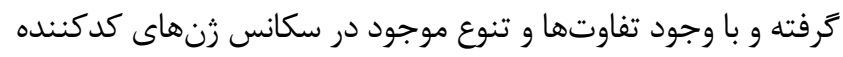

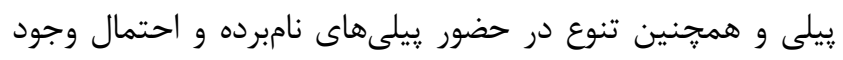

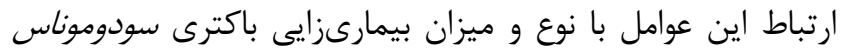

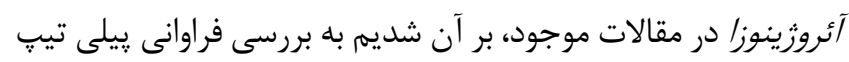

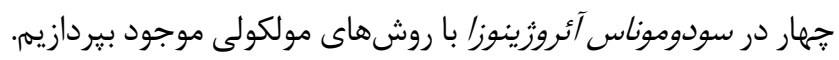

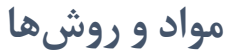

از مجموع •q نمونه سودوموناس آئروزينوزاى جداشده، فَّ نمونه

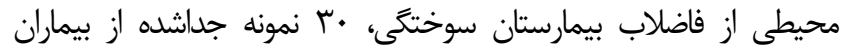

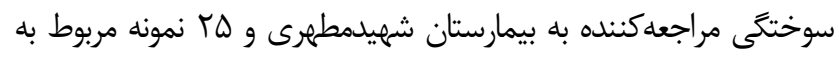
كودكان مبتلا به سيستيك فيبروزيس بيمارستان كودكان مفيد بونند. نمونهها از انتهاى سال צو تا انتهاى سال ه9 جمعآورى شند. براساس درخواست، نمونهبردارى در شرايط استريل انجام شد و در شرايط مناسب بلافاصله بهائ

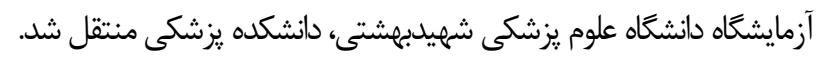
نمونههاى خلط بيمار ان مبتلا به سيستيك فيبروزيس مراجعهكنينده به بيمارستان مفيد، به محيط كشت مك كانكى آكار و آكار خوندار تلقيح دئل

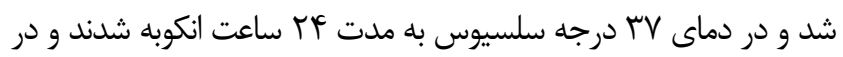

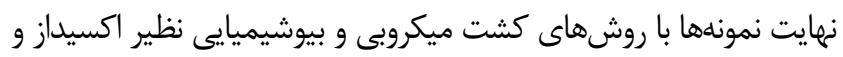

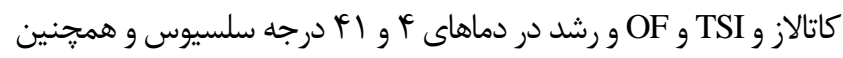

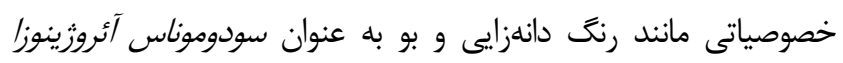

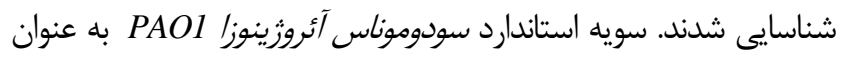
كنترل استفاده شد. نمونهاى محيطى نيز از فاضلاب بيمارستان سوختىى

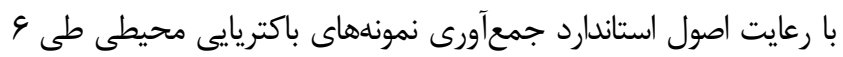

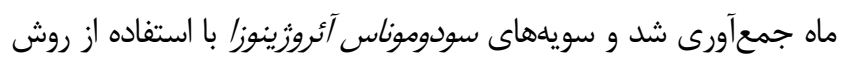

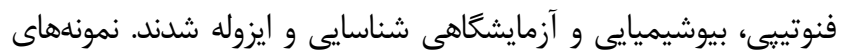

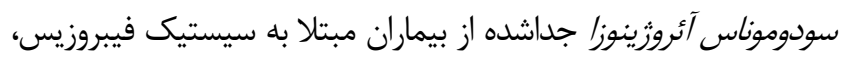

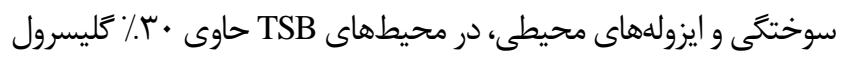
و در دماى • V درجه سلسيوس نتخهدارى شدند.
باكترىهايى است كه در آزمايشآها رشد مىكنند. دو سيسته مشخص O-Oكليكوزيلاسيون ييلى در سودوموناس آئروزينوزا تا به حال آشكار شده است. اول كليكوزيلاسيون به واسطه TfpO (PilO) اتفاق مىافتد. PilO، يك Oاليكوساكاريل ترنسفراز است كه يك واحد آنتىثن O سنتز شده به وسيله مسير توليد Lps (لييويلىساكاريد) به

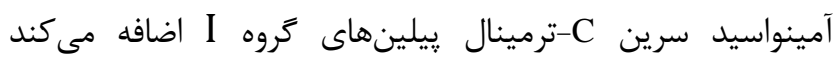

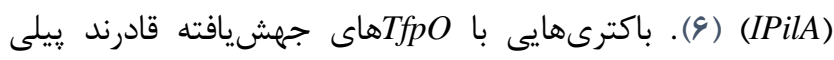
سطحى را ايجاد كنند و حركت يِيجشى از خود نشان مى دهند. اين مسئله بيانكر آن است كه كليكوزيلاسيون براى عملكرد باكترى لازم

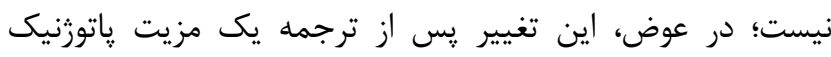

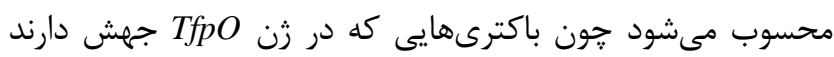
نسبت به باكترىهاى جهشنيافته داراى توانايى كمترى در ايجاد داد

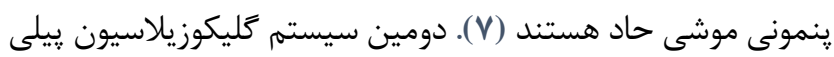

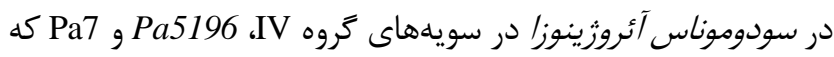
فاقد TfpO هستند يافت شد. يك سويه جهشيافته آنتىرن

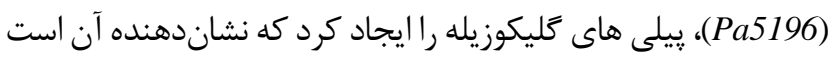

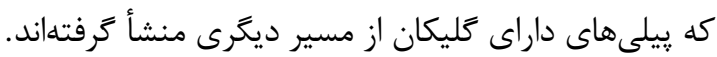

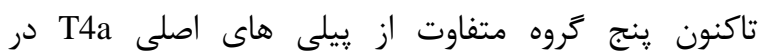

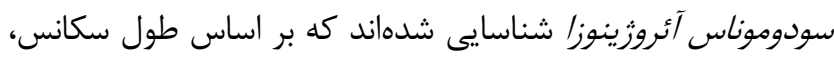

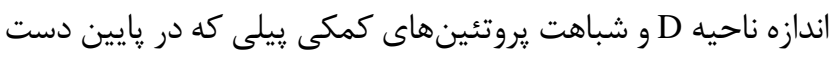

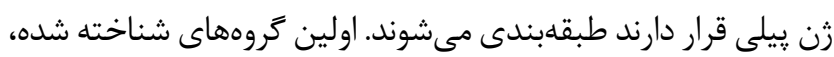

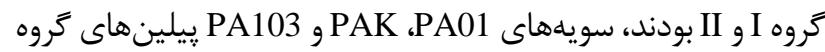
درا بيان مى كنند. اين سويهها فاقد زن هاى كمكى بين PilA2

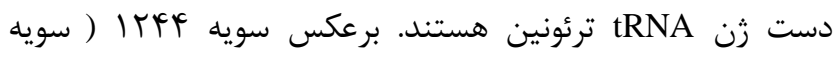

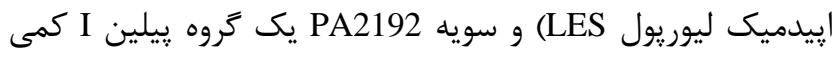
بزركتر و يك ORF اضافى بين زنهاى PilA و زنهاى tRNA

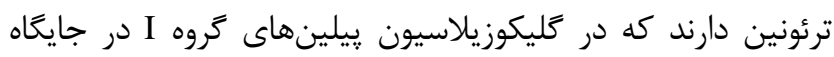

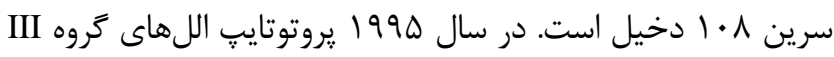
در ايزوله خاصى از سودوموناس آئروزينوزا يافت شد. اسيانج برى و

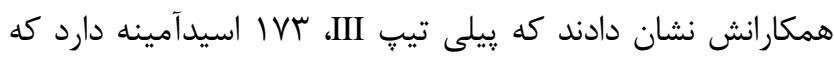

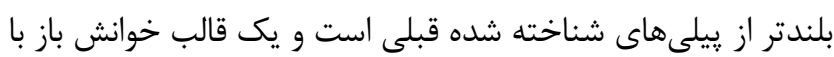
عملكرد نامشخص دارد كه امروزه TfpY ناميده مىشود و در קيايين

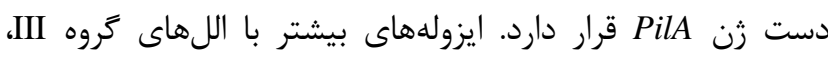

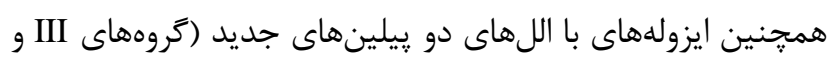

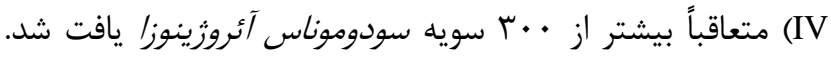

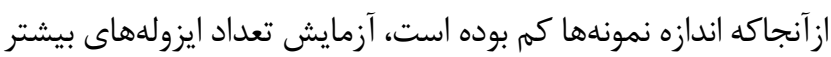

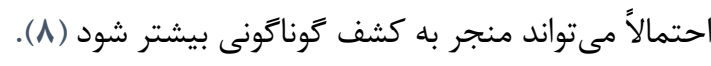


واكنش PCR در حجم PL بL و بدين شرح انجام زرفت: بافر (Amplicon, Iran) Master Mix 1x

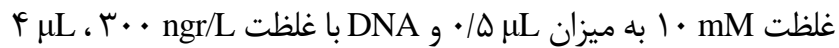
و آب مقطر ديونيزه استفاده شد. يس از تهيه و آمادهسازى، ميكروتيوبها در دستخاه توموسايكلر (Bio Intellectica, Canada) قرار داده شد. برنامه تكثير زن موردنظر براى هر كدام از سويهها در جدول r خلاصه شده است.

(Bioneer Co., با استفاده از كيت خالصسازى PCR محصولات Korea) PCR شركت Bioneer كره جنوبى انجام شد. BLAST سكانس ها با استفاده از بانك اطلاعاتى NCBI انجام شد. تحليلهاى آمارى نيز با استفاده از نرمافزار SPSS نسخه سب انجام شد.

\section{استخراج DNA و واكنش زنجيرهاى يليمراز}

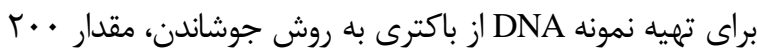
ميكروليتر از آب مقطر استريل را در داخل ميكروتيوب ريخته و از

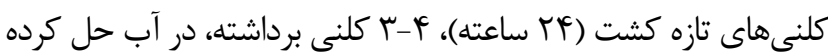

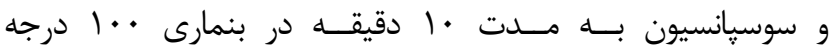

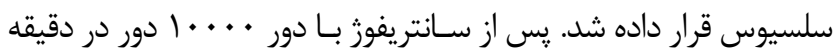
به مدت ه دقيقه، محلول رويى حاوى DNA براى انجام PCR به ميكروتيوب جديـد منتقل شد. در مطالعه ما بررسى وجود زنهاى كدكننده سه زيرگروه ييلى نوع جهارم شامل زنهاى TfpO و TfpZ با روش PCR و با استفاده از يرايمرهاى اختصاصى ذكر شده در جدول شماره ا انجام شد.

جدول ا. سكانس نوكلئوتيدى يرايمرهاى زنهاى TfpO و TfpZ از زير كونههاى بيلى تيب IV

\begin{tabular}{|c|c|c|c|}
\hline 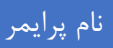 & 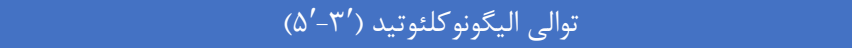 & طول محصول(bp) & مرجع \\
\hline TfpO & $\begin{array}{c}\text { Forward 5'- CGTAGGGCTTGCACTGCTAT-3' Reverse 5'- } \\
\text { AAGAACCCTCCCAACACGAC-3' }\end{array}$ & 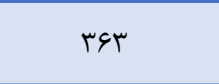 & اين مطالعه \\
\hline$T f p Z$ & $\begin{array}{l}\text { Forward 5'- AGATTAGGGCGTTCGCTGTT-3' } \\
\text { Reverse 5'- CCGCAGGACATCCATTAGCA-3' }\end{array}$ & f\&t & اين مطالعه \\
\hline
\end{tabular}

جدول r. برنامه اجرايى تكثير و شناسايى ثنهاى TfpOgTfpZ

\begin{tabular}{|c|c|c|c|c|}
\hline زن & \multicolumn{2}{|c|}{$T f p O$} & \multicolumn{2}{|c|}{$T f p Z$} \\
\hline مراحل & $\left({ }^{\circ} \mathrm{C}\right)$ & زمان & دما ( & زمان \\
\hline دناتوراسيون اوليه & 90 & ها دقيقه & 90 & ها دقيقه \\
\hline دناتوراسيون & 90 & • ب ثانيه & 90 & • بانيه \\
\hline اتصال & VT & ب بانيه & Vr & ا دقيقه \\
\hline طويلسازى & $\Delta \Lambda$ & 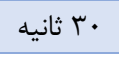 & 4. & أ \\
\hline طويلسازى نهايى & VT & V & Vr & V V V V V \\
\hline جرخه & ra & $r \Delta$ & ro & ra \\
\hline
\end{tabular}

بر اساس تفكيك گروههاى مورد مطالعه ميان فراوانى TfpO در هر

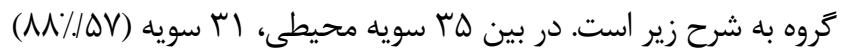

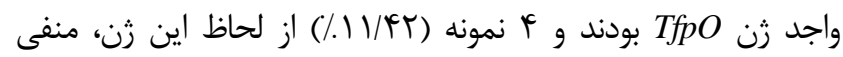
شناسايى شدند. در بين ها سويه ايزوله شده از بيماران سيستيك لهوله

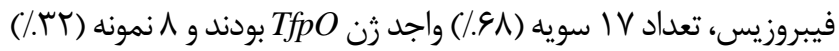
از لحاظ اين رن، منفى شناسايى شدند. همجنين در بين سودوموناس

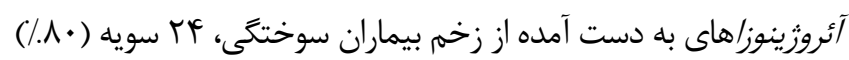

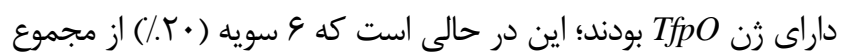

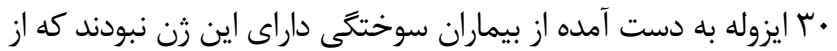
لحاظ آمارى ارتباط معنى دارى نشان ندادند (ه • / > P).

\section{كافتها}

از مجموع · • نمونه سودوموناس آئروزينوزاى جداشده، هـ نمونه محيطى، · ب نمونه جداشده از بيماران سوختخى و له نمونه مربوط به سيستيك فيبروزيس بودند. بر اساس نتايج به دست آمده،

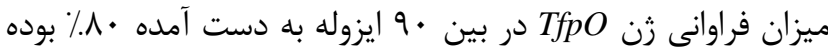

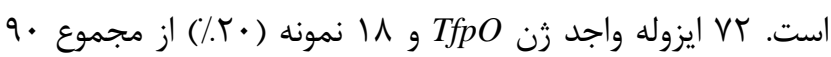

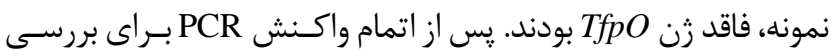
safe روى زل آثارز حايش باندها الكتروفورز محصولات PCR انجام شد و نتايج با دستخاه staining

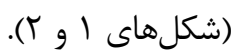


سويه ايزولهشده از بيماران سيستيك فيبروزيس، تمام سويهها از لحاظ

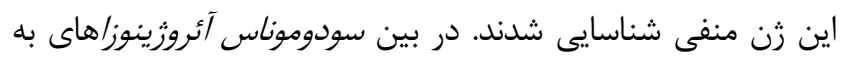

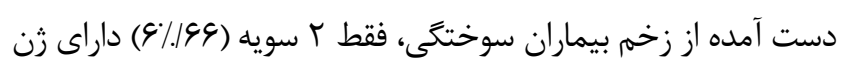

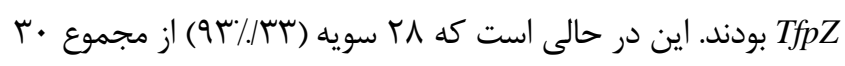

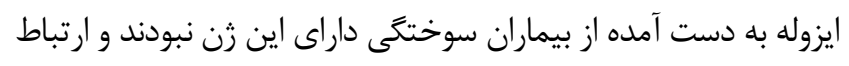

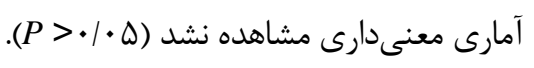

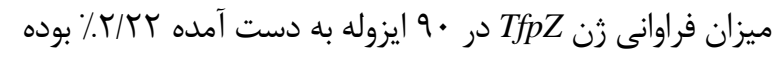

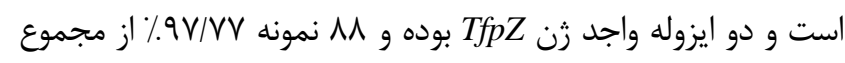

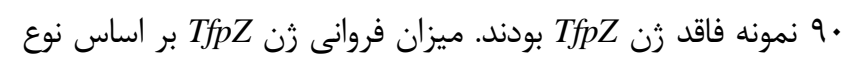

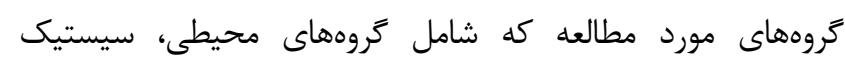

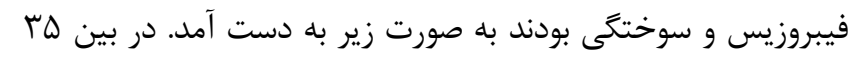

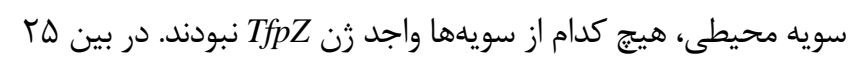

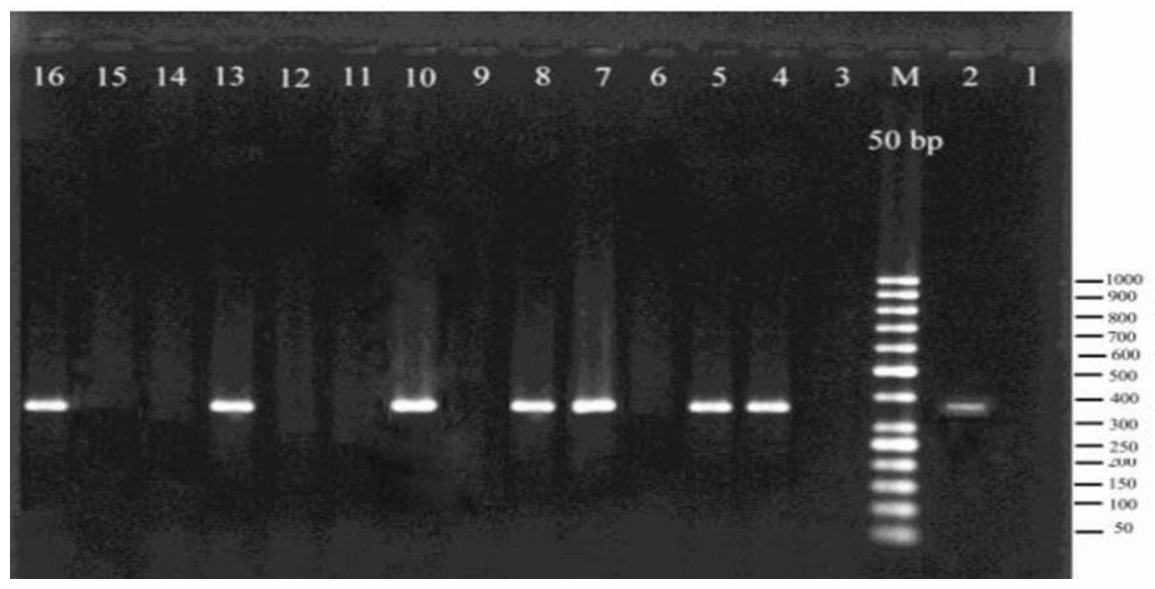

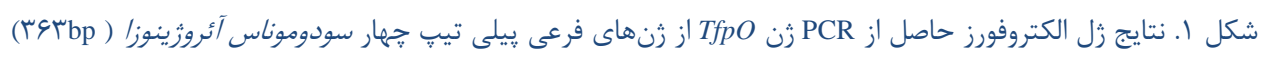

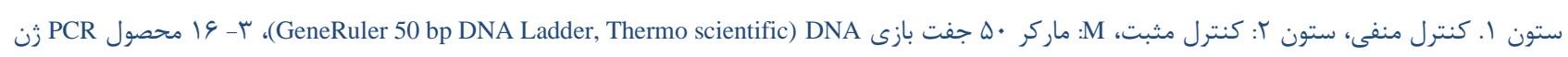

TfpO

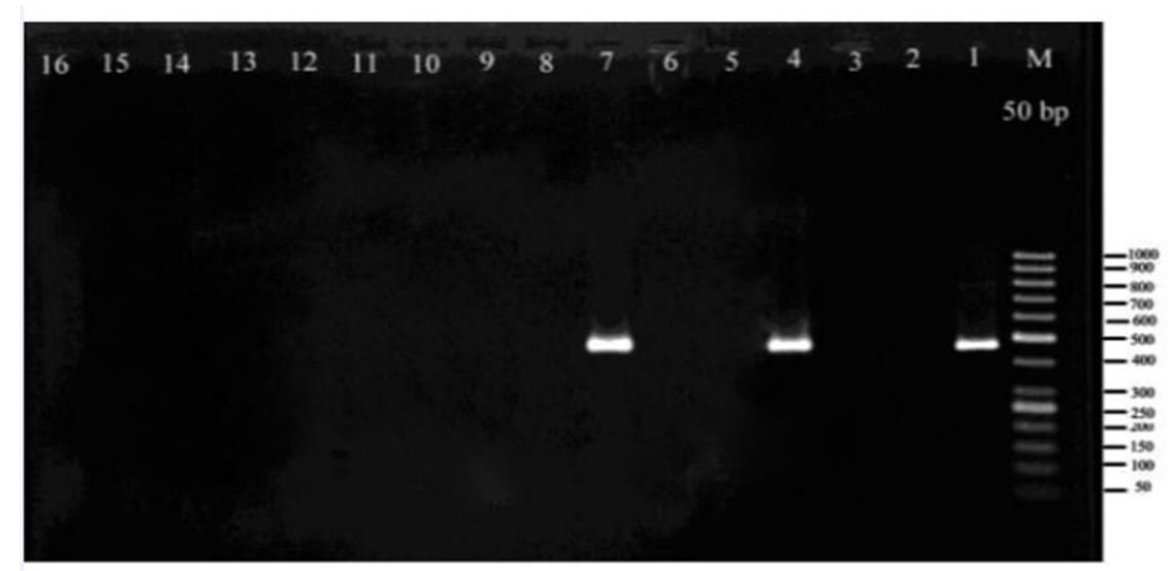

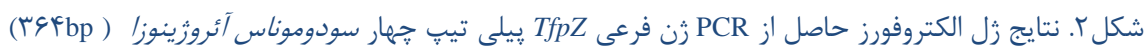

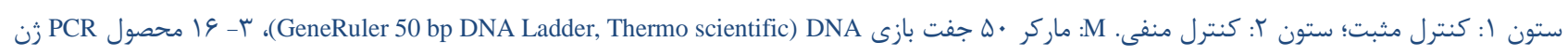

) TfpZ

ترانسيوزونها و ديخر عناصر قرار مىدهد (سا). اين در حالى است كه

بحث

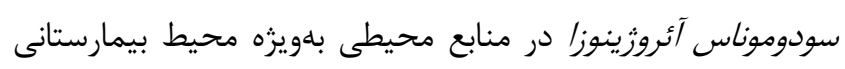

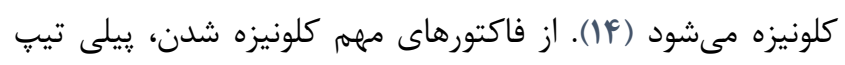

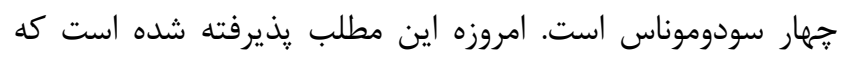

بروز قابليت بالاى سازگارى و حيات در محيطهاى متنوع،

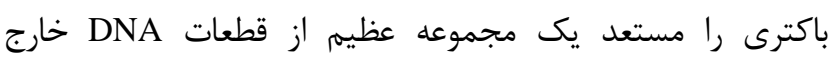

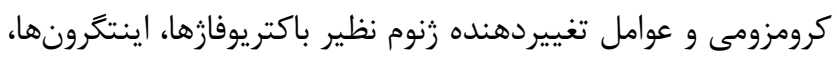


مطالعه ما بيشترين ميزان TfpO در نمونههاى سيستيك فيبروزيس

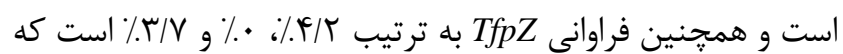
در مقايسه با مطالعه ما بيشترين يافتهها نيز در نمونههاى بيمارستانى

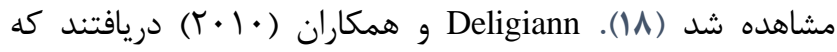

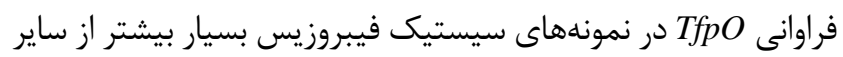
كروهها است و در ارتباط با كلونيزه شدن باكترى است (19). همجنين

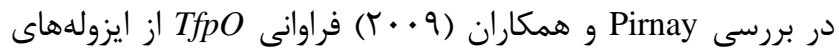

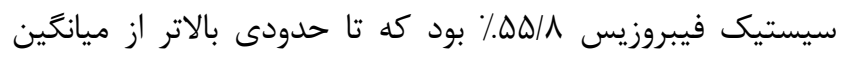

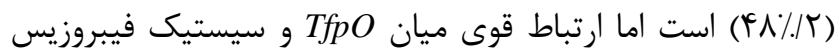
برخلاف مطالعه انجام شده مشاهده نكرديد (•r). در مطالعه حاضر، آناليز نتايج نشان داد كه گروه V V ييلى تيب

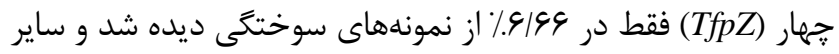

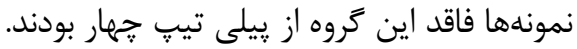

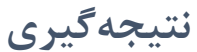

در مجموع، مطالعه ما نشان داد شيوع گروه I ييلى تيٍ جهارم (TfpO)

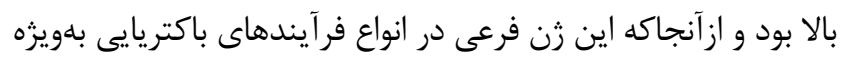

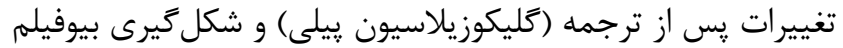

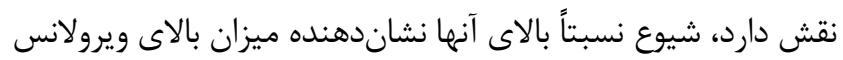

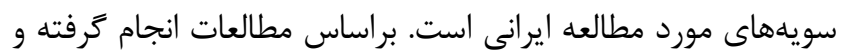
نتايج به دست آمده بيشنهاد مىشود: حجم جامعه مورد مطالعه افزايش يابد؛ طيف جامعه متنوعتر شود؛ نمونهها بر اساس روشهاي

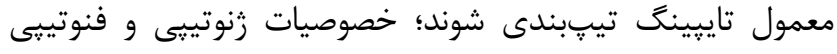

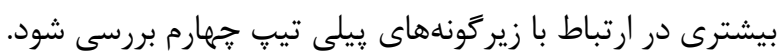

$$
\text { سياسخزارى }
$$

بدينوسيله از همكارى صميمانه گروه ميكروبشناسى دانشكده يزشكى دانشخاه علوم بزشكى شهيد بهشتى تشكر مى كنيم.

\section{تعارض منافع}

بين نويسندكان تعارض در منافع ززارش نشده است.

\section{References}

1. McCallum M, Tammam S, Little DJ, Robinson H, Koo J, Shah M, et al. PilN Binding Modulates the Structure and Binding Partners of the Pseudomonas aeruginosa Type IVa Pilus Protein PilM. Journal of biological Chemistry. 2016: 291, 11003-11015. [DOI:10.1074/jbc.M116.718353] [PMID] [PMCID]
سودوموناس آئروزينوزا قادر به بيان سه نوع مشخص و مجزا از

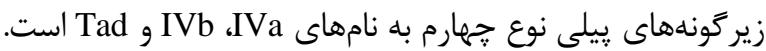
ييلى تيب IVa شايعترين نوع آن در باكترىهايى است كه در

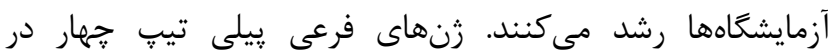

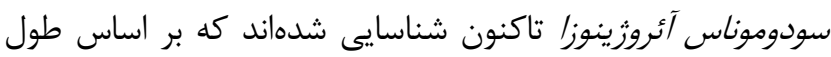
سكانس، اندازه ناحيه D و شباهت يروتئينهاى كمكى ييلى به له كروه طبقابندى مىشود و در كليكوزيلاسيون ييلى تيب جهار نقش دارند.

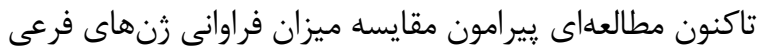
ييلى نوع جهارم در بين سويهها و جمعيتهاى سودوموناس آئروزينوزا انجام نشده است و تنها بررسىهاى محدودى در زمينه گوناكونى

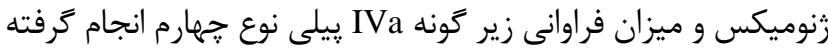

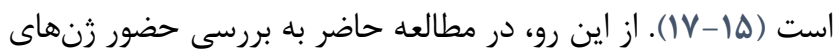
فرعى קيلى تيٍ جهارم به روش PCR در بين جامعه سودوموناس آئروزينوزاهاى ايزوله شده از بيماران سيستيك فيبروزيس، سوختكى بئى

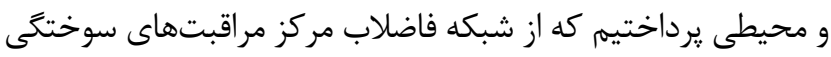

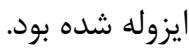

با توجه به نتايج به دست آمده، درصد قابلتوجهى از سويههاى سودوموناس آئروزينوزاى جدا شده از منابع مختلف در اين مطالعه،

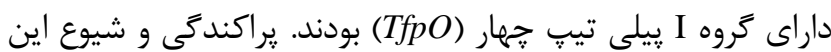

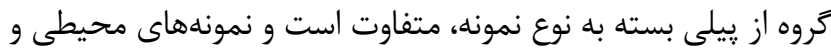

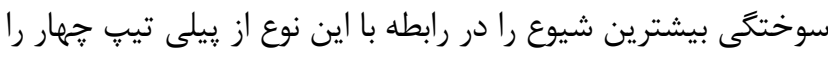

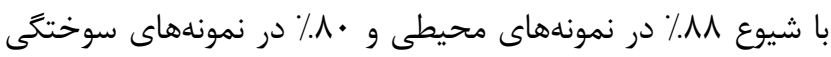

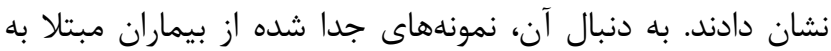

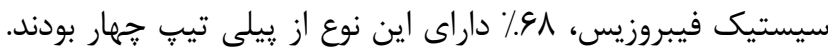

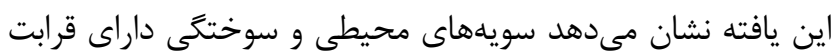
بيشترى نسبت به سويههاى جدا شده از سيستيك فيبروزيس هستند.

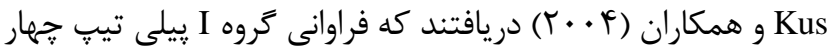

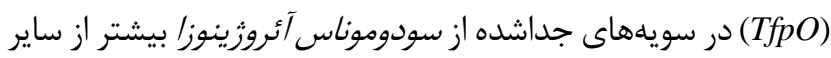
كروهها بوده است و باعث كلونيزاسيون اوليه در بيماران سيستيك آندان فيبروزيس مىشود (V) و منشأ سودوموناس آئروزينوزا در بيماران سيستيك فيبروزيس، از محيط است. طبق مطالعه Kus و همكاران

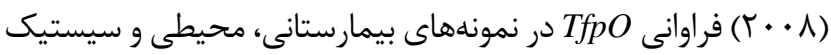

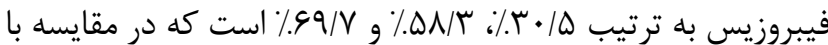

2. Buensuceso RN, Daniel-Ivad M, Kilmury SL, Leighton TL, Harvey H, Howell PL, et al. Cyclic AMPIndependent Control of Twitching Motility in Pseudomonas aeruginosa. Journal of bacteriology. 2017; 199(16):e00188-17. [DOI:10.1128/JB.00188-17] [PMID] [PMCID] 
3. Ortega DR, Fleetwood AD, Krell T, Harwood CS, Jensen GJ, Zhulin IB. Assigning chemoreceptors to chemosensory pathways in Pseudomonas aeruginosa. PNAS. 2017: 114 (48) 12809-12814. [DOI:10.1073 /pnas.1708842114] [PMID] [PMCID]

4. Gold VA, Salzer R, Averhoff B, Kühlbrandt W. Structure of a type IV pilus machinery in the open and closed state. Elife. 2015; 4:e07380. [DOI:10.7554/ eLife.07380] [PMID] [PMCID]

5. Leighton TL, Mok MC, Junop MS, Howell PL, Burrows LL. Conserved, unstructured regions in Pseudomonas aeruginosa $\mathrm{PilO}$ are important for type IVa pilus function. Scientific reports. 2018; 8:2600. [DOI:10.1038/s41598-018-20925-w] [PMID] [PMCID]

6. Tan RM, Kuang Z, Hao Y, Lee F, Lee T, Lee RJ, Lau GW. Type IV Pilus Glycosylation Mediates Resistance of Pseudomonas aeruginosa to Opsonic Activities of the Pulmonary Surfactant Protein A. Infection and Immunity 2015; 83(4): 1339-46. [DOI:10.1128/IAI .02874-14] [PMID] [PMCID]

7. Kus JV, Tullis E, Cvitkovitch DG, Burrows LL. Significant differences in type IV pilinallele distribution among Pseudomonas aeruginosa isolates from cystic fibrosis (CF) versus non-CF patients. Microbiology. 2004;150(Pt 5):1315-26. [DOI:10.1099/mic.0.26822-0] [PMID]

8. Smedley JG, 3rd, Jewell E, Roguskie J, Horzempa J, Syboldt A, Stolz DB, et al. Influence of pilin glycosylation on Pseudomonas aeruginosa 1244 pilus function. Infection and immunity. 2005;73(12):792231. [DOI:10.1128/IAI.73.12.7922-7931.2005] [PMID] [PMCID]

9. Asikyan ML, Kus JV, Burrows LL. Novel proteins that modulate type IV pilus retractiondynamics in Pseudomonas aeruginosa. Journal of bacteriology. 2008;190(21):7022-34. [DOI:10.1128/JB.00938-08] [PMID] [PMCID]

10. Saderi H, Lotfalipour H, Owlia P, Salimi H. Detection of Metallo- $\beta$-Lactamase producing pseudomonas aeruginosa isolated from burn patients in Tehran, Iran. Lab Medicine. 2010;41(10):609-12. [DOI:10.1309/LM QJF9J3T2OAACDJ]

11. Ranjbar R, Owlia P, Saderi H, Mansouri S, JonaidiJafari N, Izadi M, et al. Characterization of Pseudomonas aeruginosa strains isolated from burned patients hospitalized in a major burn center in Tehran, Iran. Acta Medica Iranica. 2011;49(10):675-9.

12. Boujari Nasrabadi MR, Hajia M. Multidrug-resistant Pseudomonas aeruginosa strains in Tehran Reference Burn Hospital, Tehran, Iran. African Journal of Microbiology Research 2012; 6(7):1393-6. [DOI:10.5897/AJMR11.1048]
13. Cohen-Cymberknoh M, Gilead N, Gartner S, Rovira S, Blau H, Mussaffi H, et al. Eradication failure of newly acquired Pseudomonas aeruginosa isolates in cystic fibrosis. Journal of Cystic Fibrosis. 2016: 15(6): 776782. [DOI:10.1016/j.jcf.2016.04.006] [PMID]

14. Schwartz T, Volkmann H, Kirchen S, Kohnen W, Schon-Holz K, Jansen B, et al. Real-time PCR detection of Pseudomonas aeruginosa in clinical and municipal wastewater and genotyping of the ciprofloxacinresistant isolates. FEMS microbiology ecology. 2006; 57(1):158-67.

[DOI:10.1111/j.1574-6941.200 6.00100.x] [PMID]

15. Basso P, Ragno M, Elsen S, Reboud E, Golovkine G, Bouillot S, et al. Pseudomonas aeruginosa PoreForming Exolysin and Type IV Pili Cooperate To Induce Host Cell Lysis. American society for microbiology. 2017; 8(1): e02250-16. [DOI:10.1128/ $\underline{\text { mBio.02250-16] [PMID] [PMCID] }}$

16. Streeter K, Katouli M. Pseudomonas aeruginosa: A review of their Pathogenesis and Prevalence in Clinical Settings and the Environment. Infect Epidemiol Med. 2016; 2(1): 25-32. DOI: 10.18869/m odares.iem.2.1.25 [DOI:10.18869/modares.iem.2.1.25]

17. Allison TM, Conrad S, Castric P. The group I pilin glycan affects type IVa pilus hydrophobicity and twitching motility in Pseudomonas aeruginosa 1244. Microbiology. 2015; 161(9): 1780-1789. [DOI:10.1099 /mic.0.000128] [PMID] [PMCID]

18. Kus J. Diversity of Pseudomonas aeruginosa type IV pilins and identification of a novel D-arabinofuranose post-translational modification. 2008. (Doctoral dissertation).

19. Deligianni E, Pattison S, Berrar D, Ternan NG, Haylock RW, Moore JE, et al. Pseudomonas aeruginosa Cystic Fibrosis isolates of similar RAPD genotype exhibit diversity in biofilm forming ability in vitro. BMC Microbiology. 2010; 10(38): 1471-2180. [DOI:10.1186/1471-2180-10-38] [PMID] [PMCID]

20. Pirnay JP, Bilocq F, Pot B, Cornelis P, Zizi M, Van Eldere $\mathrm{J}$, et al. Pseudomonas aeruginosa population structure revisited. PLoS ONE. 2009; 4(11): e7740. [DOI:10.1371/journal.pone.0007740] [PMCID] 